\title{
Paramedian thoracic epidural training model
}

\author{
Ban C. H. Tsui, MD · Jenkin Tsui
}

Received: 12 July 2011/Accepted: 4 August 2011/Published online: 16 August 2011

(C) Canadian Anesthesiologists' Society 2011

\section{To the Editor,}

Placement of a thoracic epidural requires a high level of skill and is a challenging procedure to perform. ${ }^{1}$ In adults, the effectiveness of ultrasound guidance for thoracic epidural placement is limited as the bony anatomy of this region restricts and obstructs ultrasound visualization of the epidural space. ${ }^{2}$ For this reason, anesthesiologists continue to rely on a tactile approach with either a loss of resistance method or a hanging drop technique, both of which result in challenging needle insertion due to the angle required to access the thoracic epidural space. Most anesthesiologists find the paramedian approach ${ }^{3}$ to be the most effective technique for thoracic epidural placement. The technique involves the following steps:

1. Insert the epidural needle $1-2 \mathrm{~cm}$ lateral to the spinous process of the vertebra;

2. Advance the needle perpendicular to the skin until it contacts the lamina;

3. Redirect the needle approximately $15^{\circ}$ medially to "walk off" the lamina; and

4. Angle the needle cephalad and continue the "walk off" technique to locate the epidural space. Steps 3 and 4 must be performed separately, as the epidural space may be missed if the needle is "walked off" diagonally (i.e., medial and cephalad).

This procedure can be difficult to master. Accurate placement of the needle requires fine motor skills which are best learned through hands-on practice. Phantom models have been developed to allow trainees to refine their needle guidance skills for various procedures throughout their

B. C. H. Tsui, MD ( $\varangle) \cdot$ J. Tsui

University of Alberta, Edmonton, AB, Canada

e-mail: btsui@ualberta.ca training. ${ }^{4}$ Since no phantom model is currently readily available for the paramedian approach to a thoracic epidural, we designed a simple and economical phantom which alerts the trainee immediately when the needle contacts the epidural space.

The phantom was created by molding plasticine onto a thoracic spine model. First, an adult spine model (Adult Spine Model, Directional learning, Elora, ON, Canada) (Fig. 1) was obtained. Next, all of the plastic soft tissue structures (including nerves and ligaments) were removed so that only the bony elements remained. A stainless steel water pipe (1/2" in diameter and 12" long) was then bent and fitted into the centre lumen of the spinal model (Fig. 1). The curvature of the spine model held the metal rod in place. Plasticine was then molded onto the dorsal surface at a depth of 6-7 cm and was levelled horizontally to simulate the spinal muscle and subcutaneous tissue of the back. This provides a satisfactory surface area for needle insertion and the "walk off" approach as described above. Finally, a ground electrode was connected to the metal pipe, and another electrode was connected to an insulated $17 \mathrm{G}$ Tuohy needle (Stimucath ${ }^{\mathrm{TM}}$ Continuous Nerve Block Set, Arrow International, Reading PA, USA). The nerve stimulator (Stimuplex ${ }^{\circledR}$ HNS 12, B-Braun, Melsugen, Germany) signals (e.g., current: $0.6 \mathrm{~mA}$; pulse width: $0.10 \mathrm{msec}$; frequency: $2 \mathrm{~Hz}$ ) the exact moment the needle touches the metal pipe, simulating dural contact as the epidural needle "walks off" the lamina into the epidural space (Fig. 2).

This phantom model has several advantages, including that it is inexpensive and easy to maintain. Needle tracks from repeated punctures are removed easily by remoulding the plasticine. Furthermore, the depth of the plasticine covering the spine model can be increased to simulate an obese patient, and finally, immediate feedback is provided 

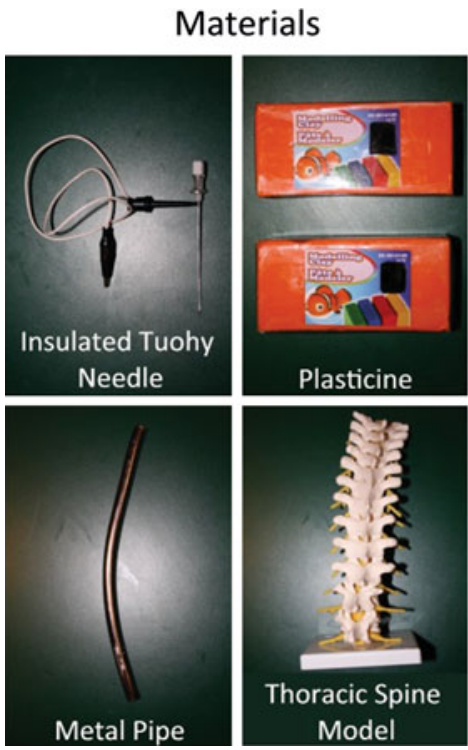

Fig. 1 Training model setup

Needle Not In Contact

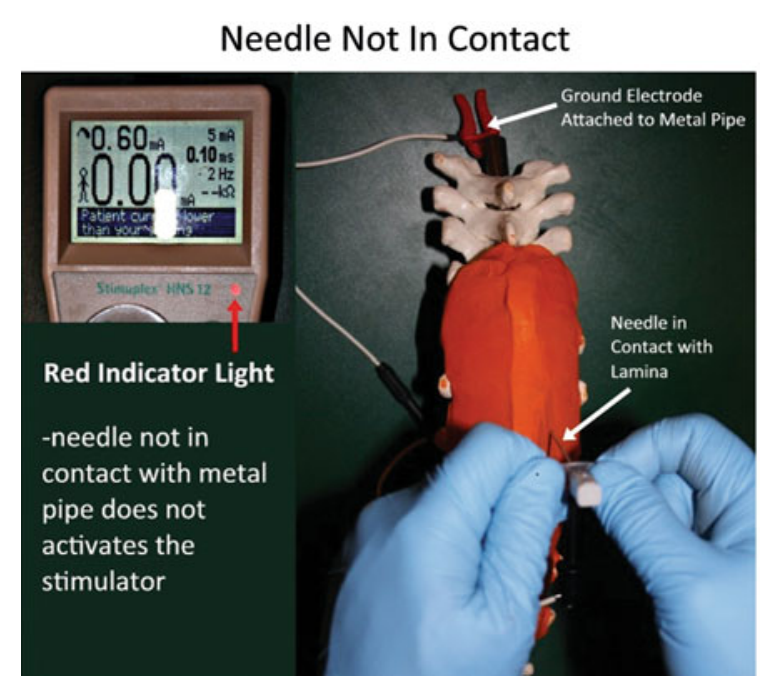

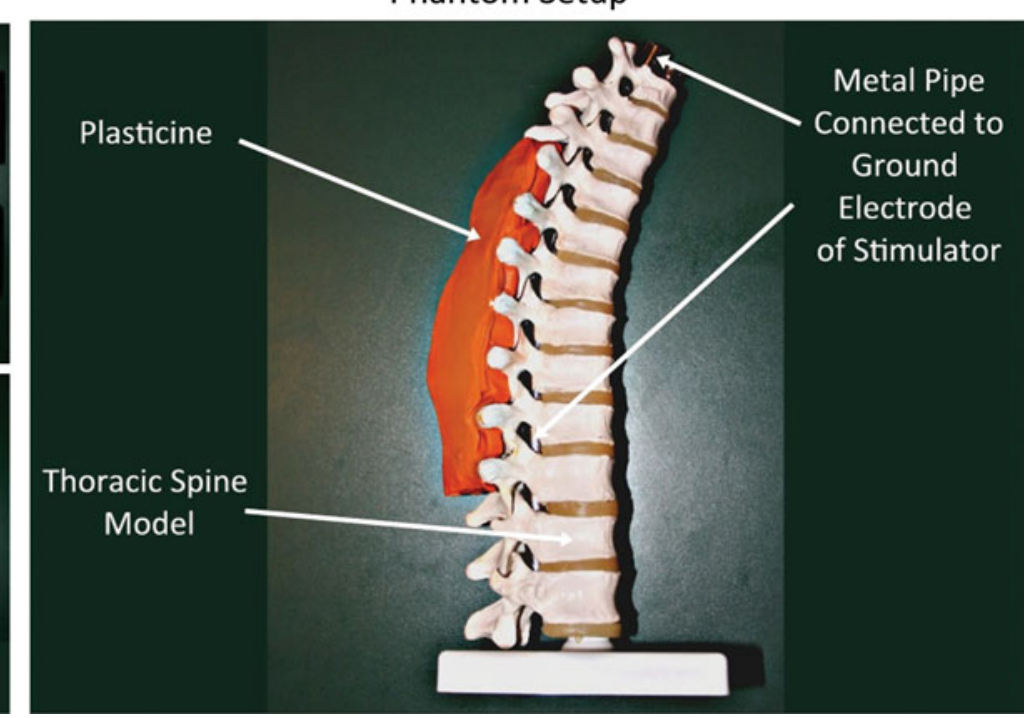

Phantom Setup

Training model st

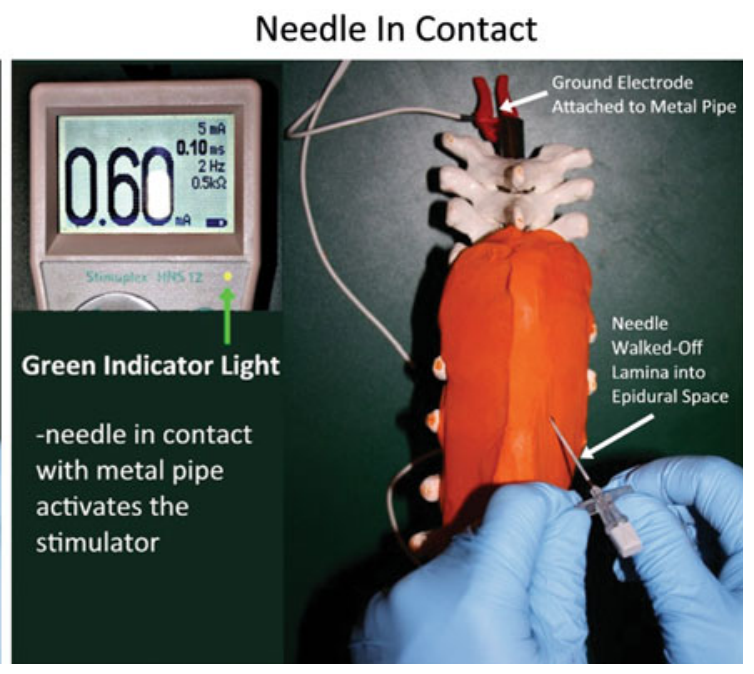

Fig. 2 Training model in use

when the needle tip enters the simulated epidural space. While this model allows the learner to practise "walking off" the lamina, it does not provide the opportunity to practise the loss of resistance technique. Also, this model does not reproduce the tactile feeling of different tissue resistances encountered when a thoracic epidural block is performed in a patient. We have used this model as a teaching tool from 1999 to the present with positive learner feedback. It has been used with hundreds of trainees in a number of regional anesthesia workshops at provincial and national meetings. This initial experience suggests that further validation of this model is warranted to evaluate outcomes (successful thoracic epidural placement).

\section{References}

1. Nagaro $T$, Yorozuya $T$, Kamei $M$, Kii $N$, Arai $T$, Abe $S$. Fluoroscopically guided epidural block in the thoracic and lumbar regions. Reg Anesth Pain Med 2006; 31: 409-16.

2. Rasoulian A, Lohser J, Najafi M, Rafii-Tari $H$, et al. Utility of prepuncture ultrasound for localization of the thoracic epidural space. Can J Anesth 2011; doi: 10.1007/s12630-011-9548-9.

3. Wantman A, Hancox $N$, Howell PR. Techniques for identifying the epidural space: a survey of practice amongst anaesthetists in the UK. Anaesthesia 2006; 61: 370-5.

4. Hocking G, Hebard S, Mitchell CH. A Review of the benefits and pitfalls of phantoms in ultrasound-guided regional anesthesia. Reg Anesth Pain Med 2011; 36: 162-70.

\footnotetext{
Conflicts of interest None declared.
} 